\title{
Steroid responsiveness in connective tissue diseases
}

\author{
HANNAH GASTON, ${ }^{1}$ M. J. ABSOLON, ${ }^{1}$ O. A. THURTLE, ${ }^{2}$ and M. A. SATTAR ${ }^{2}$ \\ From the 'Southampton Eye Hospital and the ${ }^{2}$ Rheumatology and Rehabilitation Department, \\ Southampton General Hospital
}

SUMMARY Thirty-four patients with connective tissue diseases used dexamethasone drops $0 \cdot 1 \%$ in one eye for 6 weeks. There was a higher incidence of positive steroid response than would be expected in a normal population. Most of the male patients were responders. Care should be exercised when prescribing local steroids for these patients. Males should be offered regular screening for glaucoma.

Eye involvement is a prominent feature of connective tissue diseases (CTD). Keratoconjunctivitis sicca (KCS) is the commonest complication, occurring in $11 \%$ of patients with rheumatoid arthritis (RA) ${ }^{1}$ and sporadically in systemic lupus erythematous (SLE), progressive systemic sclerosis (PSS), polymyositis, and psoriatic arthritis. Scleritis appears in $0.67 \%$ of RA patients and in other cases of CTD (e.g., ankylosing spondylitis and Behçet's disease) from time to time. Uveitis is of particular importance in juvenile rheumatoid arthritis, ankylosing spondylitis, and Reiter's syndrome. Conjunctivitis is one of the diagnostic criteria for Reiter's syndrome. Proptosis, diplopia due to extraocular myopathy, corneal disturbances, optic neuritis, and retinal vascular changes may occur is SLE and lid shortening and iris atrophy in PSS. Discolouration and oedema of the lids and extraocular muscle changes occur in polymyositis and dermatomyositis and retinal vasculitis in up to $20 \%$ of patients with polyarteritis nodosa.

The large host of ocular phenomena that are reported make it unlikely that the trabecular meshwork is exempt from autoimmune inflammatory processes, though glaucoma is not a recognised complication of CTD.

The intertrabecular spaces of the 'pore' area of the trabecular meshwork are lined by a layer of mucopolysaccharide. $^{2}$ If this layer is removed by hyaluronidase, resistance to aqueous outflow falls. Topical steroids increase outflow resistance. This may be due to increased production of mucopolysaccharide

Correspondence to Mrs H. Gaston, The Eye Hospital, Wilton Avenue, Southampton $\mathrm{SO} 94 \mathrm{XN}$. from mast cells or to swelling of the mucopolysaccharide layer because of increased water binding capacity. Trapping of greater amounts of mucopolysaccharide by degenerate trabecular meshwork accounts for the increased dexamethasone effect on glaucomatous eyes.

The pressure response to steroids has been widely studied. Local steroids (dexamethasone or betamethasone) are instilled 4 times daily for 6 weeks. 4-5\% of the normal population show a dramatic rise in intraocular pressure (IOP). ${ }^{34}$ Almost all individuals with primary open-angle glaucoma show a dramatic response to steroids. ${ }^{5}$ On the basis of genetic and family studies it has been postulated that a dramatic response to steroids identifies a predisposition to develop open-angle glaucoma. ${ }^{35} \mathrm{~A}$ positive corticosteroid provocative test is the result of trabecular damage. ${ }^{6}$

Following the observation of one of us (M.J.A.) that some patients with CTD showed a marked rise in IOP when treated with local steroids we felt that corticosteroid provocative testing might be used to determine whether patients with CTD do sustain damage to their trabecular meshwork.

\section{Patients and methods}

Thirty-four patients (11 male, 23 female) with connective tissue diseases (mainly RA) were entered in the study (Table 1). Patients with diabetes mellitus, thyroid disease, high myopia, a family history of glaucoma, Krukenberg's spindle, IOP greater than 22 $\mathrm{mmHg}$ at the start of the study, or other signs of 
Table 1 Data of 34 patients

\begin{tabular}{|c|c|c|c|c|c|c|c|c|}
\hline \multirow{3}{*}{$\begin{array}{l}\text { Patient } \\
1 . \\
2 .\end{array}$} & \multirow{2}{*}{$\frac{\text { Age }}{63}$} & \multirow{2}{*}{$\begin{array}{l}\text { Sex } \\
\mathrm{F}\end{array}$} & \multirow{2}{*}{$\begin{array}{l}\text { Diagnosis } \\
\text { RA }\end{array}$} & \multicolumn{4}{|c|}{ HLA type } & \multirow{2}{*}{$\begin{array}{l}\text { Response to steroids } \\
\text { None }\end{array}$} \\
\hline & & & & A1 & A25 & B8 & B18 & \\
\hline & & $\mathbf{M}$ & $\begin{array}{l}\text { Seronegative } \\
\text { polyarthritis }\end{array}$ & & & & & Dramatic \\
\hline 3. & 50 & $\mathbf{F}$ & $\begin{array}{l}\text { Seronegative } \\
\text { polyarthritis }\end{array}$ & A1 & A35 & BW44 & & None \\
\hline 4. & 61 & $\mathbf{F}$ & Polyarthritis & A3 & AW24 & $\begin{array}{l}\text { Bw44 } \\
\text { B8 }\end{array}$ & $\begin{array}{l}\text { B15 } \\
\text { B13 }\end{array}$ & $\begin{array}{l}\text { None } \\
\text { Intermediate }\end{array}$ \\
\hline 5. & 64 & $\mathbf{M}$ & RA & A3 & A11 & B7 & B27 & Intermediate \\
\hline 6. & 59 & $\mathrm{~F}$ & RA & A2 & A28 & B27 & BW48 & None \\
\hline 7. & 49 & $\mathrm{~F}$ & ?SLE & A1 & A11 & B8 & BW35 & None \\
\hline \multirow[t]{2}{*}{8.} & 65 & $\mathrm{~F}$ & $\begin{array}{l}\text { Primary biliary } \\
\text { cirrhosis/psoratic }\end{array}$ & & & & & \\
\hline & & & arthropathy & A2 & AW31 & BW44 & BW35 & None \\
\hline 9. & 61 & $\mathbf{F}$ & $\mathbf{R A}$ & A1 & A3 & B8 & B40 & None \\
\hline 10. & 64 & $\mathbf{M}$ & $\begin{array}{l}\text { Seronegative } \\
\text { polyarthritis }\end{array}$ & A2 & AW32 & B8 & B18 & Intermediate \\
\hline 11. & 43 & $\mathbf{M}$ & RA & A2 & A28 & B8 & BW44 & Intermediate \\
\hline 12. & 53 & $\mathbf{M}$ & RA & A2 & A28 & B8 & BW44 & Dramatic \\
\hline 13. & 59 & $\mathbf{M}$ & RA & A1 & A26 & B8 & B27 & None \\
\hline 14. & 53 & $\mathrm{~F}$ & RA & A2 & & B40 & & None \\
\hline \multirow[t]{2}{*}{15.} & 71 & $\mathbf{M}$ & RA/ankylosing & & & & & \\
\hline & & & spondylitis & A11 & AW24 & B7 & B27 & Dramatic \\
\hline 16. & 63 & $\mathbf{M}$ & RA. & A1 & A11 & B8 & BW55 & Dramatic \\
\hline 17. & 61 & $\mathrm{~F}$ & RA & A3 & A28 & BW44 & BW35 & Intermediate \\
\hline 18. & 57 & $\mathrm{~F}$ & RA & A2 & AW24 & B7 & B27 & None \\
\hline 19. & 63 & $\mathrm{~F}$ & Polyarthritis & A3 & A28 & B27 & BW35 & None \\
\hline \multirow[t]{2}{*}{20.} & 64 & $\mathrm{~F}$ & Seronegative & & & & & \\
\hline & & & polyarthritis & A1 & AW31 & B8 & B27 & None \\
\hline 21. & 60 & $\mathbf{F}$ & RA & A1 & A26 & B8 & B27 & None \\
\hline 22. & 67 & $\mathbf{F}$ & RA & A28 & & B5 & B18 & None \\
\hline 23. & 55 & M & RA & A2 & A11 & & BW44 & Dramatic \\
\hline 24. & 35 & $\mathrm{~F}$ & RA & & A28 & B15 & B40 & None \\
\hline 25 . & 64 & $\mathrm{~F}$ & RA & A1 & A3 & B13 & BW49 & None \\
\hline 26. & 20 & $\mathrm{~F}$ & RA & A1 & A2 & B8 & BW44 & None \\
\hline 27. & 48 & $\mathrm{~F}$ & RA & A3 & AW32 & B14 & B15 & None \\
\hline 28. & 69 & $\mathrm{~F}$ & RA & A11 & & B17 & BW22 & None \\
\hline 29. & 78 & $\mathrm{~F}$ & RA & A2 & A11 & B5 & BW44 & None \\
\hline \multirow[t]{2}{*}{30.} & 54 & $\mathbf{M}$ & Seronegative & & & & & \\
\hline & & & polyarthritis & A1 & A3 & B8 & B14 & None \\
\hline 31. & 61 & $\mathrm{~F}$ & RA & A2 & AW31 & BW44 & BW49 & None \\
\hline 32. & 73 & $\mathbf{M}$ & RA & A1 & A3 & B8 & BW35 & Intermediate \\
\hline 33. & 53 & $\mathrm{~F}$ & RA & A2 & AW30 & B13 & BW50 & None \\
\hline 34. & 54 & $\mathrm{~F}$ & RA & A2 & AW32 & B40 & BUSV & Intermediate \\
\hline
\end{tabular}

glaucoma were excluded, as were those currently taking systemic steroids.

Visual acuity determination, direct ophthalmoscopy, slit-lamp microscopy, and applanation tonometry were performed on both eyes at the first visit. Patients were asked to instill dexamethasone drops $0.1 \%$ in the right eye (RE) 4 times daily for 6 weeks. Both eyes were re-examined 3 and 6 weeks later at the same time of day. The same tonometer was used at each visit. All measurements were performed by one observer (H.G.). Patients were asked to reattend if they experienced discomfort, blurring, or haloes. The trial was discontinued immediately a dramatic rise in IOP occurred. Full HLA typing was carried out on all patients.

We classified patients' response to dexamethasone as follows: (1) dramatic: a rise in IOP (RE) to 32
mmHg or more; (2) intermediate: IOP (RE) at 6 weeks between 25 and $31 \mathrm{mmHg}$; (3) nonresponse: IOP (RE) at 6 weeks $24 \mathrm{mmHg}$ or less. The pressures in the left eye acted as a control to ensure that changes in IOP (RE) were due to dexamethasone alone.

\section{Results (Table 2)}

Five patients (15\% of the total) were dramatic responders. They were all male. Seven patients $(20 \%)$ were intermediate responders; $4(57 \%)$ were male and 3 were female. Twenty-two patients $(65 \%)$ were nonresponders; $2(9 \%)$ were male and 20 were femalè.

There was no correlation between the steroid responsiveness of the patients and their ESR, sheep cell agglutination titre, or the duration of their 
Table 2 Steroid response of 34 patients with connective tissue disease

\begin{tabular}{|c|c|c|c|c|c|c|c|c|}
\hline \multirow[t]{2}{*}{ - } & \multicolumn{2}{|c|}{ Nonresponders } & \multicolumn{2}{|c|}{ Intermediate } & \multicolumn{2}{|c|}{ Dramatic } & \multicolumn{2}{|c|}{ Total } \\
\hline & No. & $\%$ & No. & $\%$ & No. & $\%$ & No. & $\%$ \\
\hline Male & 2 & 9 & 4 & 57 & 5 & 100 & 11 & 32 \\
\hline Female & 20 & 91 & 3 & 43 & 0 & 0 & 23 & 68 \\
\hline Total & 22 & 100 & 7 & 100 & 5 & 100 & 34 & 100 \\
\hline
\end{tabular}

disease. The HLA types of the 34 patients did not differ significantly from those of a normal control panel.

The chi-square test ${ }^{7}$ was used to show that the percentage of dramatic responders in the patient group $(15 \%)$ was significantly greater than that in normal population studies $\left(4 \%^{3}-5 \% \%^{4}\right): \chi^{2}=6 \cdot 04$, $\mathrm{DF}=1, \mathrm{p}<0.02$. The test for trend in proportions ${ }^{8}$ was used to show that with increasing response to steroids there was an increasing proportion of males: $\chi^{2} \mathrm{~T}=17 \cdot 84, \mathrm{DF}=1, \mathrm{p}<0 \cdot 001$.

\section{Discussion}

Bernstein and Schwartz $z^{9}$ found that 48 patients taking oral steroids for RA, skin diseases, and collagen diseases had a higher IOP than age- and sex-matched controls not taking steroids. They attributed this to the effect of systemic steroids, but none of the controls had RA or collagen diseases. In contrast Belousna ${ }^{10}$ found that 60 patients taking systemic steroids for collagen diseases had a lower IOP than normal. No studies have been reported on the IOP of patients with collagen diseases who were not taking systemic steroids.

Becker $^{3}$ and Armaly ${ }^{4}$ have shown that $4-5 \%$ of the normal population show a dramatic response to local steroids, and they appear to be more at risk of developing open-angle glaucoma. $15 \%$ of our patients had a dramatic response to steroids, which is a significant difference. We used similar methods and entry criteria to their studies so that our figures and theirs should be roughly comparable. The use of ageand sex-matched controls, though theoretically desirable, would have exposed more individuals to the inherent risks of local steroids.

Five of our patients were dramatic responders. They were all male. One had seronegative polyarthritis. The other 4 had rheumatoid arthritis. One of these (patient 15) had both RA (typical clinical changes in, for instance, the hands and sheep cell agglutination test (SCAT) positive) and ankylosing spondylitis (stiff back, bilateral erosive changes in the sacroiliac joints, HLA B27 positive). This is a combination which is rare but has been described. ${ }^{11} 12$ $\mathrm{He}$ did not have rheumatoid nodules, but the peripheral arthritis of ankylosing spondylitis is not associated with rheumatoid factor.

Seven of our patients were intermediate responders, and $4(57 \%)$ of these were males. Five had RA; the other 2 had negative or insignificant SCAT titres.

The remaining 22 patients were nonresponders. Only $2(9 \%)$ of these were male.

Thus there was a striking trend for dramatic or intermediate response in the males with CTD, whereas a sex difference in steroid responsiveness has not been recorded in the other studies.

We conclude that damage to the trabecular meshwork may be yet another possible ocular complication of CTD, and glaucoma may result from it. Certainly local steroids should be given with great circumspection in males with CTD, as they are likely to develop ocular hypertension after a few weeks' treatment. This is particularly relevant because many of the other ocular complications of CTD are treated with steroids.

We thank Dr M. I. D. Cawley and Dr J. R. Preston, of the Rheumatology Department, who allowed us to study their patients; Mr David Tate, who performed the HLA typing; Mr David Machin for statistical advice; Mrs M. Robinson, librarian; and Miss K. L. Rodger for secretarial help.

\section{References}

1 Williamson J. Incidence of eye disease in cases of connective tissue disease. Trans Ophthalmol Soc UK 1974; 94: 742-9.

2 Armaly MF. Effect of corticosteroids on intraocular pressure and fluid dynamics. Arch Ophthalmol 1963; 70: 482-91.

3 Becker B. Intraocular pressure response to topical corticosteroids. Invest Ophthalmol Visual Sci 1965; 4: 198-205.

4 Armaly MF. Statistical attributes of the steroid hypertensive response in the clinically normal eye. Invest Ophthalmol Visual Sci 1965; 4: 187-97.

5 Becker B, Hahn KA. Topical corticosteroids and heredity in primary open-angle glaucoma. Am J Ophthalmol 1964; 57: 543-51.

6 Akingbehin T. Corticosteroid provocative tests. Trans Ophthalmol Soc UK 1982; 102: 253-6.

7 Armitage P. Statistical methods in medical research. Oxford: Blackwell, 1974: 112.

8 Armitage P. Statistical methods in medical research. Oxford: Blackwell, 1974: 364.

9 Bernstein HN, Schwartz B. Effects of long term systemic steroids 
on ocular pressure and tonographic values. Arch Ophthalmol 1962; 68: 742-53.

10 Belousna ZF. On the hydrodynamics in eyes of patients with collagenoses in treatment with corticosteroids. Vestn Oftalmol $1978 ; 4: 47-8$.
11 Huskisson EC. Ankylosing spondylitis and rheumatoid arthritis. Proc R Soc Med 1970; 63: 620.

12 Alexander EL, Bias WB. Arnett FC. The coexistence of rheumatoid arthritis with Reiter's syndrome and/or ankylosing spondylitis. J Rheumatol 1981; 8: 398-404. 